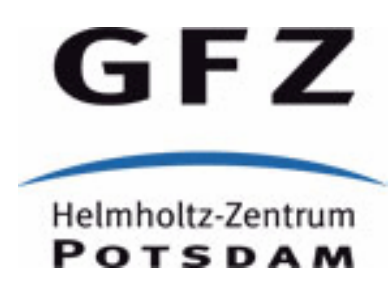

Originally published as:

Xiong, X., Shan, B., Zheng, Y., Wang, R. (2010): Stress transfer and its implication for earthquake hazard on the Kunlun Fault, Tibet. - Tectonophysics, 482, 1-4, 216-225

DOI: $10.1016 /$ j.tecto.2009.07.020 


\section{Stress transfer and its implication for earthquake hazard on the Kunlun Fault, Tibet}

2 Xiong XIONG ${ }^{\mathrm{a} * *}$ Bin SHAN $^{\mathrm{a}, \mathrm{b}}$ Yong $\mathrm{ZHENG}^{\mathrm{a}}$ Rongjiang $\mathrm{WANG}^{\mathrm{c}}$

$3{ }^{a}$ Key Laboratory of Dynamic Geodesy, Institute of Geodesy and Geophysics, Chinese Academy of Sciences, 4 Wuhan 430077, China

$5{ }^{b}$ Graduate University, Chinese Academy of Sciences, Beijing 100049, China

$6 \quad{ }^{c}$ GFZ German Research Centre for Geosciences, D-14473 Potsdam, Germany

\section{Abstract}

10 recognized as one of the major left-lateral strike-slip faults bounding the Tibetan Plateau,

11 and ranked one of the most active faults in China continent. During the past hundred years,

12 over twenty strong earthquakes occurred along and near the Kunlun Fault, including six

13 large earthquakes $(M>7)$. Since some major highly-populated and industrialized cities are

14 close to the Kunlun Fault, understanding of stress transfer and earthquakes migration along

15 the Kunlun Fault is most important for assessing seismic hazard in this region. In this study, by integrating coseismic effect, viscoelastic relaxation and tectonic loading, we

17 studied the evolution of the regional Coulomb stress field by analyzing a sequence of 18 strong earthquakes along the Kunlun Fault. We studied the stress evolution over one 19 century by analysing a sequence of five earthquakes $(M \geq 7)$ that occurred along the Kunlun 20 Fault since 1937. The model of dislocation sources embedded in a mixed elastic/inelastic

21 layered half-space was used, and the layered model and relevant parameters were 22 constrained by seismic studies. Fault rupture locations and geometry, as well as slip 23 distribution of earthquakes were taken from field observations and seismic studies.

\footnotetext{
${ }^{*}$ Corresponding author. Tel.: +86 27 68881331; fax: +8627 68881362

E-mail address: xxiong@asch.whigg.ac.cn (Xiong XIONG)
} 
24 Numerical results showed a good correlation between stress transfer, accumulation 25 and earthquakes occurrence. All four studied earthquakes occurred after the 1937 Tuosuo

26 Lake quake were encouraged by the preceding earthquakes with positive stress loading. In 27 subject to the choice of the earthquake source parameter two or three out of four events 28 occurred in regions that experienced previous coseismic and postseismic stress changes of 29 at least $0.01 \mathrm{MPa}$, suggesting that earthquake triggering due to stress transfer has occurred 30 along the Kunlun Fault. The total stress change since 1937 of the Kunlun Fault region has 31 lead to high levels of stress accumulated on the Xidatan-Dongdatan segment and Maqin32 Maqu segment, which have not experienced any significant large earthquake over at least 33 several hundred or several thousand years.. The accumulated stress raises the potential 34 earthquake hazard in these areas. Our study demonstrated the crucial importance of 35 postseismic viscoelastic relaxation in the stress transfer and accumulation following large 36 earthquakes.

37 Keywords: Stress transfer; Stress accumulation; Earthquake triggering; Earthquake hazard 


\section{Introduction}

The Kunlun Fault (KF), extending about $1600 \mathrm{~km}$ between $86^{\circ} \mathrm{E}$ and $105^{\circ} \mathrm{E}$, is one of

41 the largest strike-slip faults in the northern Tibet (Fig. 1) (Van Der Woerd et al., 2000, 42 2002a). Fieldwork confirms that the E-W to WNW-ESE striking KF is a major strike-slip 43 fault that accommodates for both, the northeastward shortening and the eastward extrusion of Tibet (e.g., Tapponnier and Molnar, 1997; Yin and Harrison, 2000). It is suggested that the differential motion of $10-20 \mathrm{~mm} / \mathrm{yr}$ between the north Tibet and south-central Tibet is mostly accommodated by the KF as seismic slip (Lin et al., 2006). As a result, the KF has experienced strong earthquakes, including six $M \geqslant 7$ events in the last 100 years (Fig. 1). Since there are several major highly-populated and industrialized cities close to the KF, such as Golmud and Delinhar, and recent events appear to be propagating towards some 50 populated areas, understanding of earthquakes migration along the $\mathrm{KF}$ is most important for assessing seismic hazard in this region.

The earthquake sequence along the KF (Table 1) shows evidence for time-space progression, suggesting certain interaction among earthquakes. Interaction between earthquakes is suggested to realize in a manner of earthquake triggering by the change of Coulomb Failure Stress ( $\triangle \mathrm{CFS}$ ) (Stein 2003): positive $\triangle \mathrm{CFS}$ brings the fault closer to failure and thus earthquake occurrence, while negative $\triangle \mathrm{CFS}$ retards subsequent events 57 (Stein 1999; Freed, 2005).

A number of studies have successfully used the Coulomb model to explain aftershock distribution (King et al., 1994; Reasenberg and Simpson 1992; Parsons et al. 1999; Toda et al., 1998; Wyss and Wiemer 2000; Ma et al., 2005), earthquake sequences (Stein et al. 1994; Hodgkinson et al. 1996; Nalbant et al. 1998), and triggering of moderate to large 
earthquakes (Harris et al., 1995; Deng and Sykes, 1996; Jaume and Sykes, 1996; Martínez-

63 Díaz et al., 2006) as well as to assessing earthquake risk (McCloskey et al., 2005; Nalbant et al., 2005). However, a limitation of most of these models is that they only consider elastic responses to fault slip, and thus cannot account for delay times in the triggering process (Freed and Lin, 2001; Freed 2005). Postseismic stress changes due to viscoelastic stress relaxation in the lower crust and/or upper mantle were taken into account to explain aftershock distribution and the triggering of later events at the time scale of years and decades (Deng et al., 1999; Freed and Lin, 2001; Pollitz and Sacks, 2002). Recently, a number of models incorporating postseismic viscoelastic relaxation have been developed and applied successfully on study the triggering of earthquake pairs and sequences (Pollitz et al., 2003; Lorenzo-Martín et al., 2006; Ali et al., 2008)

Similar elastic (Chen et al., 2003) or viscoelastic Coulomb models (Shen et al., 2003) were published for the KF region. However, some source parameters and the rheological model commonly employed by these works were not well constrained. New evidence from further studies carried out in the last few years should be incorporated to constrain the coseismic slip, rock properties and stratification. Moreover, various mechanisms responsible for $\triangle \mathrm{CFS}$ should be incorporated toward a comprehensive understanding of the earthquake interaction. Therefore, a study integrating coseismic and postseismic stress change together with tectonic loading (e.g., Lorenzo-Martín et al., 2006; Freed et al., 2007; Ali et al., 2008)

81 is expected to re-evaluate the process of stress evolution and nature of earthquake on the 82 KF.

In this study, we investigated a sequence of five earthquakes of $M \geq 7.0$ since 1937 (Table 1 and fig.1) on the KF. We studied the stress evolution since 1937 by integrating coseismic slip, postseismic viscoelastic relaxation of the lower crust and mantle, and interseismic tectonic loading due to India-Eurasia convergence. In particular, we evaluated 
87 the importance of the individual process on the total stress field. Instead of fixing the average strike direction of the KF, we took into account the details in orientation of the different ruptures and different segments of the fault. The evolution of the $\triangle \mathrm{CFS}$ at the hypocenters of the shocks, as well as the state on the rupture surfaces immediately before

91 the earthquakes were examined under different assumptions of the rheology. In addition, we extrapolated the study to 2040 to evaluate the stress state on various segments of the KF. The aim of the study is to investigate the relationship between $\triangle \mathrm{CFS}$ and seismicity, with emphasis on identifying segments on the KF that have experienced large build-up of unrelieved stress to provide useful information for seismic hazard assessment in this region.

\section{Earthquake sequence and source parameters}

100 Left-lateral motion along the KF is believed to take up a substantial fraction of the

101 northward motion of the Indian plate under Tibet by left-lateral strike-slip. This motion 102 probably initiated in the late Miocene or early Pleistocene (Kidd and Molnar, 1988; Fu and 103 Awata, 2004). The total slip along the KF is about $75 \mathrm{~km}$, based on the offset of a meta104 sedimentary unit interpreted from Landsat images (Kidd and Molnar 1988). The late 105 Quaternary slip rate on the KF is $12 \pm 3 \mathrm{~mm} / \mathrm{yr}$, derived from cosmogenic dating of offset 106 stream risers. This estimation is supported by further cosmogenic surface dating and

107 radiocarbon dating (Van der Woerd et al., 2002b; Li et al., 2005), and trenching surveys 108 (Zhao, 1996), as well as GPS measurements (Wang et al., 2001). Given a uniform rate of $10912 \mathrm{~mm} / \mathrm{yr}$ since its initiation, the magnitude of slip along the KF implies that the KF has 110 been active over the past $7 \mathrm{Ma}$ (Yin and Harrison, 2000). 
111 However, no earthquake was instrumentally recorded on the KF before the 1900s.

112 During the twentieth century, the seismicity of the KF was sparse but continuous with

113 several moderate and large earthquakes. There are 19 earthquakes of $\mathrm{M} \geq 5$ occurred on the

114 Kunlun fault since 1900: 6 events of $M \geq 7,1$ of $M=6.3$ and 12 of $M<5.5$. Since it is 115 suggested that moderate earthquakes $(6.0 \leq \mathrm{Mw}<6.5)$ only perturb the stress locally $(10 \mathrm{~s}$ of $116 \mathrm{~km})$ (Freed et al., 2007) and given that our focus is on the evolution of stress over a broad 117 region, it is reasonable to assume that local perturbation of small to moderate earthquakes 118 are insignificant for the overall stress pattern. Therefore, in the present study, we only 119 considered the earthquakes of $\mathrm{M} \geq 7$ in our analysis.

120 At the beginning of the last century, a strong earthquake of M7.0 shook Xiugou on 121 November 4, 1902 (SBQP, 1999), but few information of this earthquake is available, except the poorly located epicenter. We have to exclude it from the earthquake sequence 123 for analysis. The subsequent, the 1937 Tuosuo Lake (Huashixia) earthquake (M7.5) was 124 particular large. It ruptured the Tuosuo Lake (or Dongxi Co) segment of the fault, 125 producing a surface rupture with a length of 150-240 km long and a left-lateral slip ranging 126 4-7 m (Liu, 1999; SBQP, 1999; Van der Woerd, et al., 2002b; Guo et al., 2007). Since the 127 influence of the earthquakes before 1937 is difficult to be incorporated in the analysis due 128 to the lack of information, we set the 1937 earthquake as the first of the studied earthquake 129 sequence, and confine our purpose and interest in the interaction among the 1937 130 earthquake and subsequent events to study the interaction among them.

131 Twenty-six years later, the M7.0 Alake Lake earthquake occurred on the Alake Lake 132 segment west of the 1937 coseismic rupture segment (SBQP, 1999), causing 40 km-long rupture with 1-2 m left-lateral slip (Guo et al., 2007). The second largest earthquake in KF

134 region is the 1997 Mw7.6 Manyi earthquake, which was proceeded by the 1973 M7.3

135 Manyi earthquake occurred along the western part of the Manyi fault, a branch fault of the 
136 Kunlun fault system (Molanr and Chen, 1983; Velasco et al., 2000). The 1997 Manyi

137 earthquake produced a 170-km-long surface-rupture zone along the westernmost strand of

138 the $\mathrm{KF}\left(\sim 86^{\circ} \mathrm{E}\right.$ to $\left.88^{\circ} \mathrm{E}\right)$ with a maximum slip of $7 \mathrm{~m}$ (Peltzer et al., 1999; Van der Woerd

139 et al., 2002a,b; Xu 2000). It ruptured a fault which we interpret to be one splay of the KF

140 horse-tail west of $91^{\circ} \mathrm{E}$ (Van der Woerd, et al., 2002b). The last and largest earthquake is

141 the 2001 Mw7.8 Kokoxili (Kunlun) earthquake that produced a $400 \mathrm{~km}$-long surface-

142 rupture zone along the Kusai lake segment (Lin et al., 2002, 2003; Van der Woerd, 2002a;

143 Xu et al., 2002; Fu and Lin, 2003; Fu, et al., 2005; Lasserre et al., 2005) between the 1937

144 Tuosuo lake and 1997 Manyi surface rupture zones. The rupture length of Kokoxili

145 earthquake ranks the longest coseismic surface rupture for an intracontinental earthquake

146 ever recorded.

147 The earthquake sequence of these five events provides an excellent chance to decipher

148 how $\triangle \mathrm{CFS}$ on the KF evolved over the past several decades and how earthquakes

149 communicated with each other by stress transfer. On the other hand, it also provides a good

150 opportunity to outline the segments which have experienced large build-up of stress.

151 Source information of the earthquakes, such as focal mechanism and slip distribution,

152 is of crucial importance for stress analysis and therefore must be examined carefully. For

1531937 Tuosuo Lake earthquake, the length and slip distribution of the rupture is debated.

154 While some authors suggested a longer rupture zone $(\sim 240-300 \mathrm{~km})$ (Li et al., 2006;

155 Molnar and Deng, 1984), others favoured a shorter dimension of the rupture (150-180 km)

156 (Guo et al., 2007; Van der Woerd et al., 2002a). Both, homogeneous co-seismic slip (Guo

157 et al., 2007) and distributed co-seismic slip (Li et al., 2006) models were proposed. Since

158 convincing evidences are not available due to degradation and overlap of older

159 earthquakes, it is difficult to discern a more reliable one from several candidate models. In

160 this study, we calculated the stress changes by using the models proposed by Guo et al 
161 (2007) and Li et al (2006), and analysed the difference between the results. Strike, dip and 162 rake were chosen based on the focal mechanism determined by Molnar and Deng (1984).

163 The length and slip of the rupture segment of the 1963 Alake Lake earthquake were 164 taken from Guo et al. (2007). We inferred width of rupture by estimating rupture areas 165 with the empirical scaling laws and relationships of Wells and Coppersmith (1994). The 166 focal mechanism was taken from Molnar and Lyon-Caen (1989).

167 For 1973 Manyi earthquake, since the length, width and slip are poorly constrained, 168 we have to look for an alternative way. We modelled the earthquake as rectangular planar 169 patches with uniform slip occurring within an elastic crust. The thickness of the elastic 170 crust was assumed to be the same as that determined in the 1997 Manyi earthquake. Then, 171 we used the magnitudes together with the empirical scaling laws by Wells and 172 Coppersmith (1994) to estimate the rupture area and the slip amplitude. Strike, dip and 173 rake were taken from Molnar and Chen (1983).

174 The parameters of the Manyi earthquake determined by different authors differ significantly from each other. For example, the rupture length has been estimated to be 47

$176 \mathrm{~km}$ (Liu et al., 2000), $70 \mathrm{~km}$ (Xu and Chen, 1999), $110 \mathrm{~km}$ (Liu et al., 2002) and $170 \mathrm{~km}$ 177 (Peltzer et al., 1999; Funning et al., 2007), respectively. The width ranges from $18 \mathrm{~km}$ 178 (Funning et al., 2007), $28 \mathrm{~km}$ (Liu et al., 2000) to $63 \mathrm{~km}$ (Xu and Chen, 1999). Among the 179 various source models, the rupture length given by Liu et al (2000) and Xu \& Chen (1999) 180 (47 km and $70 \mathrm{~km}$, respectively) is much shorter than what was obtained by field survey 181 (Xu, 2000). And inconsistently, the estimated seismic moment by these authors is greater 182 than all other studies (e.g., Funning et al., 2007; Shan et al., 2002; Wang et al., 2007; 183 Peltzer et al., 1999). Therefore, the source models by Liu et al (2000) and Xu \& Chen 184 (1999) were excluded from the present study. The other source models (Funning et al., 2007; Shan et al., 2002; Wang et al., 2007; Peltzer et al., 1999) predicted similar rupture 
186 extents despite some slight differences of slip patterns, and more consistent surface rupture

187 with the evidence from field study (Xu, 2000), In our stress calculation, we used two most

188 recent models proposed by Funning et al. (2007) and Wang et al. (2007).

189 The rupture process and slip distribution of Kokoxili earthquake has been studied 190 comprehensively. Although consensus has been reach concerning the rupture length, 191 complexity of slip partitioning, detailed slip distribution differs among individual studies 192 on field investigation (e.g., Fu et al., 2005; Xu et al., 2006), InSAR imaging (Lasserre et 193 al., 2005) and teleseismic inversion. In this study, we used $5 \mathrm{~km} \times 5 \mathrm{~km}$ gridded fault model

194 and strike-slip distribution proposed by Lasserre et al. (2005) to calculate the stress field.

195 Other slip distribution models (Fu et al., 2005) were used to test the stability of numerical 196 results. The source parameters associated with all earthquakes are summarized Table 1.

\section{Model and methods}

200 (Scholz, 1990) using the expression

$$
\Delta C F S=\Delta \tau-\mu^{\prime} \Delta \sigma_{N}
$$

202 where $\tau$ is the shear stress, $\sigma_{N}$ is the normal stress and $\mu^{\prime}$ is the apparent coefficient of 203 friction. The change in shear stress $\Delta \tau$ is positive in direction of the slip of the following 204 earthquake (the observing fault); $\Delta \sigma_{N}$ is positive for increasing clamping normal stress with pressure defined positive. The equation implies that regional faults that lie in areas of positive $\triangle \mathrm{CFS}$ are brought closer to failure, whereas faults that lie in areas of negative

$207 \Delta$ CFS are brought further away (Freed 2005). 
In this study, we calculated the evolution of $\triangle \mathrm{CFS}$ in the KF region by considering contributions from coseismic, postseismic and tectonic loading since the 1937 Tuosuo

210 Lake earthquake. To calculate the coseismic and postseismic stress, we used the model of

211 dislocation sources embedded in a mixed elastic/inelastic layered half-space (Wang et al.,

212 2003, 2006). In contrast to Okada (1992), our model allows us to implement a more

213 realistic rheology, so that postseismic effects can be studied. In fact, the Okada model

214 (1992) is the special case of a homogeneous elastic half-space (see Wang et al. 2003 for

215 details of comparison). We also employed the code PSGRN/PSCMP (Wang et al., 2006),

216 by which surface and subsurface deformation due to the common geophysical sources in a

217 multi-layered viscoelastic-gravitational half-space can be easily determined. In our

218 modelling, the earth surface was treated as plane. The geometric deviation of the spherical

219 surface from the corresponding planar surface for our studied area, that can be measured

220 by the ratio between the arc height $(\sim 60 \mathrm{~km})$ and the arc length $(\sim 1700 \mathrm{~km})$, is about $3-4 \%$.

221 For such a small deviation, we may expect that its influence on the deformation field is

222 similarly small. Consequently, the difference found so far between the spherical and planar

223 earth models should not be dominated by the curvature effect but by the layering effect that

224 has been considered in our analysis. Therefore, despite large extent of our studied area

$225(\sim 1700 \mathrm{~km})$, the earth's curvature was not taken into account, although it was emphasized 226 by some studies (e.g., Pollitz 1997).

227 The magnitude and pattern of postseismic deformation and stress changes depend 228 strongly on the rheological layering of the crust and upper mantle, which in turn depends 229 on composition and ambient temperature and pressure. Seismic data show a Moho depth of $230 \sim 65 \mathrm{~km}$ in the studied area (Li et al., 2004). Since most earthquakes on the KF occurred at 231 depths shallower than 20 km, and all slip models of the Manyi (e.g., Funning et al., 2007;

232 Wang et al., 2007) and Kokoxili (Lasserre et al, 2005) earthquakes suggest that the 
ruptures extend down to a depth of $20 \mathrm{~km}$. We therefore set the thickness of elastic crust and the locking depth to be $20 \mathrm{~km}$. We assumed that viscoelastic processes occur below the depth of $20 \mathrm{~km}$. Below the depth, coseismic stress changes within the viscous lower crust and upper mantle cannot be sustained and lead to visco-elastic flow, which induces stress changes in the seismogenic crust (Hergert and Heidbach, 2007; Ali et al., 2008). In our study we use the linear Maxwell rheology to study the visco-elastic effects. Although it is suggested that some other rheological models, such as SLS (Cohen, 1982; Pollitz et al., 1998; Ryder et al., 2007), power-law, non-linear rheologies (Pollitz et al., 2001; Freed and Bürgmann, 2004) were suggested could be better to analyse post-seismic relaxation processes, we, in our opinion, are not able to discern among different rheologies. Therefore, we prefer to use the simplest and most used linear Maxwell rheology, instead of more complicated models that would add additional unknowns to our analysis.

The layered model used for our calculations is described by the parameters summarized in Fig. 2. The thickness of crustal layers, density distribution, and $V_{P}$ were taken from seismic studies, both tomography models (Li et al., 2006; Zhou et al., 2006) and deep seismic sounding experiments (Wang and Qian, 2000; Li et al., 2004). The quantities of density $\rho$ and $V_{P}$ were used to derive the shear modulus $\mu$ using the following expression (Aki \& Richards, 2002)

$$
\mu=\rho V_{s}^{2} \approx \frac{1}{3} \rho V_{P}^{2}
$$

We determined the model viscosity of lower crust and upper mantle by evidence from the studies on postseismic displacement (Ryder et al., 2007; Shao, et al., 2008). Other 254 viscosity values were used to test the stability of numerical results.

We modeled the tectonic stress loading following a procedure outlined by Lorenzo- 
257 realized by a steady slip over the depth ranging 20 to $100 \mathrm{~km}$, and the deep dislocation

258 technique proposed by Savage (1983). The fault is assumed to be locked at $20 \mathrm{~km}$ depth.

259 The slip rates increase from zero at $20 \mathrm{~km}$ depth to its full magnitude at $68 \mathrm{~km}$ depth. From

$26068 \mathrm{~km}$ to $100 \mathrm{~km}$ depth the full slip rates were applied. The magnitude of the slip on the

261 KF was taken from GPS interpretations (Chen et al., 2000; Wang et al., 2001) and was

262 indicated by numbers in rectangle overlapping on segments of fault (Fig. 1). At the end

263 segments of the fault, the tapered slip was used to minimise edge effects.

264 We considered a Poisson's ratio of 0.25 and set the apparent coefficient of friction $\mu^{\prime}$

265 to a moderate value of $\mu^{\prime}=0.4$ (King et al., 1994). Different values for $\mu^{\prime}$ were also tried to 266 test the stability of results (see 4.3 for details). We present the results of the stress change

267 calculations in terms of $\triangle \mathrm{CFS}$ values on a horizontal plane at $10 \mathrm{~km}$ depth that consists of $268141 \times 221$ grid points, corresponding to $3^{\prime} \times 6^{\prime}$ grid spacing, covering the study region 269 confined by $32^{\circ} \mathrm{N}-39^{\circ} \mathrm{N}$ and $83^{\circ} \mathrm{E}-105^{\circ} \mathrm{E}$. At each stage, we calculated the $\Delta \mathrm{CFS}$ for a the 270 fault plane orientation of the next inspected event, instead of using optimally oriented fault 271 planes or fixing the average strike direction of the KF.

\section{Numerical results}

\subsection{Stress transfer and accumulation on the KF}

We calculated the cumulative $\triangle \mathrm{CFS}$ using the parameters described above and shown in the Fig. 2. The viscosities of lower and upper mantle were set to $1 \times 10^{18}$ and $1 \times 10^{20} \mathrm{~Pa} \cdot \mathrm{s}$ respectively, which were given by studies on postseismic deformation (Ryder et al., 2007; 
models published by other authors were used for testing the stability of the results (Section $4.2)$.

The evolution of the calculated $\triangle \mathrm{CFS}$ on the KF is illustrated in the Fig.3, from the

284 beginning of the earthquake sequence to the present. Since the hypocenters of most 285 earthquakes in the KF region were confined within the depths of 10-20 km, and the maximum slip of the two large earthquakes, i.e. the 1997 Manyi and 2001 Kokoxili earthquakes, were commonly located at depths less than $10 \mathrm{~km}$, we calculated the $\triangle \mathrm{CFS}$ values on a horizontal plane at that depth. The maximum and average $\triangle \mathrm{CFS}$ at the rupture surfaces are summarized in the Table 1 and the stress evolution at the hypocenters are shown in the Fig. 4.

The snapshot series begins with the first event, the 1937 Tuosuo Lake earthquake (Fig.3a). Then, the state of the stress field is presented for time immediately before each subsequent event. The 1937 earthquake that ruptured a large portion of the central KF loaded the entire rupture surface of the 1963 Alake Lake earthquake with coseismic stress over $0.01 \mathrm{MPa}$ (Fig. 3a). The $\triangle \mathrm{CFS}$ immediately before the 1963 Alake Lake event is shown in Fig. 3b. The joint effect of elastic, and viscoelastic loading led to a stress increase 297 of up to $0.06 \mathrm{MPa}$ in average and $0.11 \mathrm{MPa}$ in maximum on the rupture surface (Table 2), which is higher than the proposed threshold value $(0.01 \mathrm{MPa})$ suggested for earthquake triggering (e.g., King et al., 1994; Stein 1999; Heidbach and Ben-Avraham, 2007). The

3001963 Alake Lake earthquake was obviously encouraged by the $\Delta$ CFS associated with the $301 \quad 1937$ event.

The coseismic stress change associated with the 1963 Alake Lake earthquake posed little impact on the overall stress pattern, except in its near-field areas (Fig. 3c). Since the 1973 Manyi earthquake was located far from the 1963 earthquake rupture, and the time 
period between events was too short for postseismic stress relaxation, our results show a

306 negligible interaction between these two events $(<0.005 \mathrm{MPa})$. Therefore, we suggested

307 that the 1973 Manyi earthquake might be a result of stress accumulation due to tectonic

308 loading.

309 The 1973 Manyi earthquake significantly changed the stress pattern of the western

310 segment of the Manyi fault (Fig. 3d). The 1997 Manyi earthquake occurred directly

311 adjacent to the 1973 Manyi earthquake. The $\triangle$ CFS increase on the rupture surface of the

3121997 Manyi event is as much as $0.063 \mathrm{MPa}$ in average due to the coseismic and 313 postseismic stress of the 1973 event (Fig. 3d and Table 2).

314 The 1997 Manyi earthquake produced negligible coseismic stress change on the 315 rupture surface $(0.001 \mathrm{MPa})$ at the hypocenter of the 2001 Kokoxili earthquake (Table 2).

316 However, the postseismic stress change caused by all preceding earthquakes reached 0.01

$317 \mathrm{MPa}$ at the hypocenter given by Harvard CMT, and $0.046 \mathrm{MPa}$ at that by USGS. Although

318 the stress loading was not significant, the entire rupture surface was loaded by positive

$319 \Delta \mathrm{CFS}$ of $0.014 \mathrm{MPa}$ in average and $0.04 \mathrm{MPa}$ in maximum. Particular, over 40 percentage

320 of the entire rupture surface was stressed over 0.01 MPa (Fig. 3e and Table 2). Therefore,

321 the Kokoxili earthquake could be encouraged by the joint effects of tectonic, elastic and

322 viscoelastic loading produced by the preceding earthquakes.

323 In order to analyse the stress transfer and to examine the contributions from co- and

324 post-seismic components in detail, we plotted the evolution of $\triangle \mathrm{CFS}$ at hypocenters of 325 each earthquake in Fig.4. Except for the 1937 Tuosuo Lake earthquake the 1963, 1973 and 3261997 earthquakes caused coseismic stress changes $<0.01 \mathrm{MPa}$. Thus, we can infer that the 327 static stress transfer is not the major control for the occurrence of subsequent events. In 328 contrast to coseismic stress change, the postseismic relaxation effect plays an important 329 role for the stress transfer, accumulation and earthquake triggering. For example, at the 
330 hypocenter of the 1963 earthquake, the postseismic stress change associated with the 1937

331 earthquake is five times larger compared to coseismic one (Fig. 4 and Table 2). The same

332 holds on for the earthquakes of 1973, 1997 and 2001, in which the effects of postseismic

333 relaxation are comparable or even much greater in magnitude than the $\triangle \mathrm{CFS}$ caused by the

334 tectonic loading (Table 2 and Fig. 4), suggesting a dominant role of the viscoelastic 335 relaxation on the earthquakes' interaction on the KF.

336 By examining the combined co- and post-seismic stress change, we test whether the 337 hypothesis of earthquake triggering is applicable to the KF. Following a scheme for 338 classifying earthquake triggering based on the $\triangle \mathrm{CFS}$ on rupture plane (Heidbach and Ben339 Avraham, 2007), we find that among the four earthquakes succeeding the 1937 Tuosuo

340 Lake earthquake, three events show potential triggering due to both the maximum and 341 average $\triangle \mathrm{CFS}$ values $\geq 0.01 \mathrm{MPa}$ (Table 2), a threshold value for earthquake triggering.

342 However, if we apply this scheme for the $\triangle \mathrm{CFS}$ at the hypocenter, 2 out of 4 events are 343 potential examples of the earthquake triggering (Table 2). For the 2001 Kokoxili 344 earthquake, there are two proposed hypocenters: one by Harvard CMT and the other by 345 USGS. The uncertainty of the earthquake location leads to a controversy: triggering is 346 applicable for Harvard CMT hypocenter, while negative for USGS one.

347 It should be noted that, however, all the four subsequent events occurred in the 348 regions that experienced positive stress loading, suggesting that the preceding earthquakes 349 prompt the occurrence of the subsequent ones.

\subsection{Stability of the results}

We tested the stability of our results by comparing different slip models, rheological assumptions and friction coefficients of faults. 
The slip models of two earthquakes, 1937 Tuosuo Lake earthquake and 1997 Manyi earthquake, are highly debated. For the 1937 Tuosuo Lake earthquake two different coseismic slip models exists (Li et al., 2006; Guo et al., 2007). The greatest controversy between two models is the western termination of the rupture, which leads to different estimations of the rupture length. Since no convincing evidence is available due to the

360 degradation and overlap of older earthquakes, it is difficult for us to discern which one is more realistic. We applied two models to conduct a comparison study, and found that the slip model of Li et al. (2007) produced a $\triangle \mathrm{CFS}$ increase which is about $\sim 18$ percent higher

363 than that calculated by the model of Guo et al. (2007). This discrepancy may be resulted

364 from the difference of the earthquake magnitudes predicted by two models $(0.13)$. The most remarkable difference between two stress fields is the contrast of $\triangle \mathrm{CFS}$ at the segment between the eastern extremity of the rupture of the 1963 Alake Lake earthquake

367 and the western termination of the rupture of the 1937 Tuosuo lake earthquake proposed by

368 Guo et al (2007). While the segment is significantly loaded ( $>0.02 \mathrm{MPa})$ using the Guo et al. (2007) model, it is completely within a stress shadow using the model suggested by Li et al. (2007). This contrast leads to significant discrepancy for evaluating the seismic

371 hazard on this segment. More paleoseismological data are needed for elucidating this

372 puzzle. However, it should be noted that, no matter what model is applied, our conclusion concerning earthquake triggering on the $\mathrm{KF}$ is applicable since the $\Delta \mathrm{CFS}$ calculated by

374 both models are of the same order in amplitude both at hypocenters and on the rupture 375 surfaces of the subsequent events.

In contrast to the case of the 1937 Tuosuo earthquake, the two co-seismic slip models 
378 both in far- and near-fields. Therefore, our conclusion is rigorous no matter what slip

379 model in used. And, our use of the slip model for present study is therefore justified.

\subsubsection{Viscosity}

382

Since viscoelastic relaxation is introduced, the viscosities of the lower crust and upper mantle are of importance for the stress calculation. In the present study, we set viscosities

384 according to the results from studies on postseismic deformation (Ryder et al., 2007; Shao

385 et al., 2008). Due to lack of continuous observation of postseismic deformation in the studied area, the viscosities of the crust and upper mantle are not well constrained.

387 Therefore, we tried other choices of viscosities to test the stability of the results. Table 3 shows the results of the test experiments with various configurations of viscosities. It is 389 shown that if the viscosity of upper mantle $\left(\eta_{m}\right)$ is fixed to be $10^{20} \mathrm{~Pa} \cdot \mathrm{s}$, the $\Delta \mathrm{CFS}$ decreases with increase of the viscosity of lower crust $\left(\eta_{c}\right)$. Similar situation is also found

391 for the case of fixed- $\eta_{m}$. In this study, $\eta_{c}$ and $\eta_{m}$ were set to be $10^{18} \mathrm{~Pa} \cdot \mathrm{s}$ and $10^{20} \mathrm{~Pa} \cdot \mathrm{s}$,

392 respectively. If a lower value of $\eta_{c}\left(10^{16}-10^{19} \mathrm{~Pa} \cdot \mathrm{s}\right)$ and $\eta_{m}\left(10^{19} \mathrm{~Pa} \cdot \mathrm{s}\right)$ (Clark et al., 2000) are introduced to describe the weak crust and hot mantle of the Tibetan Plateau, our results

394 of $\triangle$ CFS are substantially underestimated, and a higher value can be expected. It can be

395 inferred that our conclusion for earthquake triggering on the KF is rigorous under most 396 choices of the viscosities.

\subsubsection{Coefficient of friction}

The selection of an appropriate value for the apparent coefficient of friction $\mu^{\prime}$ is of

400 importance for the model application, as it modulates the contribution of the normal stress 401 to the $\triangle$ CFS. In general, $\mu^{\prime}$ is taken to be different values for different types of faults: 
402 higher values for thrust $(\sim 0.8)$ and normal ( $\sim 0.6)$ faults, while lower values $(0.2-0.4)$ for

403 strike-slip faults. Since the KF is a strike-slip fault with significant cumulative slip, shear 404 stress changes, in this kind of environment, dominate over normal ones, and $\triangle \mathrm{CFS}$ is

405 basically governed by shear component. Therefore, we chose low value of $\mu^{\prime}(0.4)$ for 406 stress modelling and performed tests with other values $(0$ and 0.6$)$ to elucidate its impact.

407 The numerical results show that some changes $(<10 \%)$ were found in the calculated stress 408 field. Compared with the uncertainties of the other parameters, such as rheology and slip 409 distribution, the influence of the friction coefficient is relatively small, especially for a 410 strike-slip fault.

4124.3 Stress accumulation and seismic hazard on the KF

413 We extended our calculation to year 2040 to study how the $\triangle \mathrm{CFS}$ accumulates on the

$414 \mathrm{KF}$ in the coming decades (Fig. 5). The most remarkable feature of the cumulated $\Delta \mathrm{CFS}$ on 415 the fault is the existence of five positive $\triangle \mathrm{CFS}$ zones, A-E (Fig. 3f and Fig. 5). Since the 416 regions where segments $\mathrm{A}$ and $\mathrm{B}$ are located are almost unpopulated, the stress 417 accumulation on these segments and the seismic hazard in the areas were not discussed in 418 the present study. The calculated $\triangle \mathrm{CFS}$ pattern on the segment D is uncertain, depending 419 on the choice of slip models. The lack of necessary information on paleoseismology and 420 micro-seismicity prevents us to explore more quantitative study. So, the state of $\Delta \mathrm{CFS}$ and 421 hazard of segment D is left as an open question. We focused our interest on the other 422 segments, $\mathrm{C}$ (XDS) and $\mathrm{E}$ (MMS), which have not experienced any significant large 423 earthquake over 300 yr (Van der Woerd et al. 2002b) and 2500 yr (SBQP, 1999; Wen et 424 al., 2007), respectively. 
Fig. 6 shows the evolution of the cumulative $\triangle \mathrm{CFS}$ on the segment XDS and MMS,

426 which are two major seismic gaps on the KF (SBQP, 1999; Wen et al., 2007). Although the 427 average earthquake recurrence interval and the age of most recent earthquake (MRE) are 428 ambiguous due to uncertainties of evidences, the XDS is believed to be of great potential 429 of large earthquake ( Mw7.6) (Guo et al., 2006).

430 The evolution of the cumulative $\triangle$ CFS on XDS is displayed in Fig.6a. It is shown that, 431 ignoring the abnormal jump due to edge effects and rupture configuration, the main part of 432 the segment will be experienced a positive $\triangle \mathrm{CFS}$ of $\sim 0.25 \mathrm{MPa}$, which is much higher than 433 the threshold of earthquake triggering. Although the $\triangle \mathrm{CFS}$ was raised about $0.7-0.8 \mathrm{MPa}$ 434 by coseismic slip of the 1963 and 2001 earthquakes, the postseismic relaxation plays a 435 more important role for increasing the $\triangle \mathrm{CFS}$. As time progresses, the postseismic 436 relaxation is expected to be dominative for raising the seismic hazard on this segment.

437 It is shown that the stress accumulation on the MMS was initiated by the coseismic 438 slip of the 1937 Tuosuo Lake earthquake, with $\triangle \mathrm{CFS}$ of $0.15 \mathrm{MPa}$ at its western extremity 439 and about $0.02 \mathrm{MPa}$ on the western part of the segment (Fig. 6b). As a result, the $\triangle \mathrm{CFS}$ on 440 MMS is substantially enhanced with maximum $(>0.4 \mathrm{MPa})$ at its western extremity. The 441 amplitude decreases rapidly from west to east, and tends to be a relatively small value 442 ( $\sim 0.2 \mathrm{MPa})$. In contrast to the $\triangle \mathrm{CFS}$ on XDS, the postseismic relaxation is near completion 443 in the following decades, although it raised $\triangle \mathrm{CFS}$ up to $0.1 \mathrm{MPa}$ in the evolution path. The 444 steady tectonic loading will dominate the build-up process of $\Delta$ CFS. And the western 445 extremity, Maqin, may be of the most potential of seismic hazard. 
We calculated the evolution of $\triangle \mathrm{CFS}$ in the KF area due to five earthquakes of $\mathrm{M} \geq 7$,

449 by integrating coseismic and postseismic stress change together with tectonic loading. We

450 found that all four earthquakes succeeding the 1937 Tuosuo Lake earthquake were 451 encouraged by positive $\triangle \mathrm{CFS}$ Two or three out of the four subsequent earthquakes were 452 potentially triggered by preceding events, depending on the choice of classification scheme 453 for earthquake triggering. However, we inferred that the static stress transfer is not the 454 major control for the occurrence of subsequent events, and the postseismic viscoelastic 455 relaxation process is more important in the stress transfer and accumulation following large 456 earthquakes.

457 From the cumulative $\triangle \mathrm{CFS}$ on the KF, we identified five segments with positive $458 \Delta$ CFS. Two segments, XDS and MMS, were emphasized for seismic hazard, as they has 459 not experienced any significant large earthquake over the past several hundred years and may be loaded with $\triangle \mathrm{CFS}$ over $0.4 \mathrm{MPa}$ in the following decades.

It should be noted that our results have ambiguities due to high uncertainties of slip

462 models, viscosities of lower crust and upper mantle, as well as incomplete catalogue of 463 historical earthquakes. More evidences from paleoseismology, further details on rock properties, as well as fault slip rate are essential to further constrain the state of stress and to assess in particular the seismic hazard of the deteced seismic gaps.

\section{Acknowledgments.}

469 We thank the guest editor Oliver Heidbach and three anonymous reviewers for their 470 insightful review and thoughtful comments that helped us greatly to improve the focus and 471 quality of the manuscript. This work was supported by the Chinese Academy of Sciences 
472 by grant KZCX3-SW-153, and National Natural Science Foundation by grant 40474028 .

473 The GMT software (Wessel and Smith, 1998) was used to prepare all figures. 
475 Aki, K., Richards, P. G., 2002. Quantitative Seismology Second Edition, 73pp.University Science Books California, USA.

477

478

479

480

481

482

483

484

485

486

487

488

489

490

491

492

493

494

495

496

497

Ali, S.T., Freed, A. M., Calais, E., Manaker, D. M., McCann, W. R., 2008. Coulomb stress evolution in Northeastern Caribbean over the past 250 years due to coseismic, postseismic and interseismic deformation. Geophys. J. Int. 174, 904-918 doi: 10.1111/j.1365-246 X.2008.03634.x.

Chen, B., Jiang, Z., Che, S., Wang, Q., Zhu, G., Wang, J., 2003. Study of triggering action between Mani (Ms7.9) and Kunlun (Ms8.1) great earthquake and their dynamic background. Earthquake Research in China. 19(1), 1-7.

Chen, Z., Burchfiel, B. C., Liu, Y., King, R. W., Royden, L. H., Tang, W., Wang, E., Zhao, J., Zhang, X., 2000. Global positioning system measurements from eastern Tibet and their implications for India/Eurasia intercontinental deformation. J. Geophys. Res. $105,16,215-16,227$.

Clark, M. K. and Royden, L., H., 2000, Topographic ooze: Building the eastern margin of Tibet by lower crustal flow. Geology, 28(8), 703-706.

Cohen, S.C., 1982. A multilayer model of time-dependent deformation following an earthquake on a strike-slip fault. J. Geophys. Res. 87(B7), 5409-5421.

Deng, J., Sykes, L. R., 1996. Triggering of 1812 Santa Barbara earthquake by a great San Andreas shock: Implications for future seismic hazards in southern California. Geophys. Res. Lett. 23, 1155-1158.

Deng, J., Hudnut, K., Gurnis, M., Hauksson, E., 1999. Stress loading from viscous flow in the lower crust and triggering of aftershocks following the 1994 Northridge, California, earthquake. Geophys. Res. Lett. 26 (21), 3209-3212. 
Freed, A.M., 2005. Earthquake triggering by static, dynamic and postseismic stress transfer. Annu. Rev. Earth Planet. Sci. 33, 335-367.

Freed, A.M., Ali, S.T., Bürgmann, R., 2007. Evolution of stress in Southern California for the past 200 years from coseismic, postseismic and interseismic stress changes. Geophys. J. Int., 169(3), 1164-1179.

Freed, A.M., Bürgmann, R., 2004. Evidence of power-law flow in the Mojave desert mantle. Nature 430 (6999), 548-551.

Freed, A.M., Lin, J., 2001. Delayed triggering of the 1999 Hector Mine earthquake by viscoelastic stress transfer. Nature 411 (6834), 180-183.

Fu, B., Awata, Y., 2004. When the Kunlun Fault began its left lateral strike-slip faulting: evidence from cumulative offset of basement rocks and geomorphic features. Himalayan Journal of Sciences 2, 132.

$\mathrm{Fu}, \mathrm{B} ., \mathrm{Lin}, \mathrm{A} ., 2$ 2003. Spatial distribution of the surface rupture zone associated with the 2001 Ms 8.1 central Kunlun earthquake, northern Tibet, revealed by satellite remote sensing data. Int. J. Rem. Sens. 24, 2191-2198.

513 Fu, B., Awata, Y., Du, J., Ninomiya, Y., He, W., 2005. Complex geometry and segmentation of the surface rupture associated with the 14 November 2001 great Kunlun earthquake, northern Tibet, China. Tectonophysics 407, 43-63.

516 Funning, G. J., Parsons, B., Wright, T., 2007. Fault slip in the 1997 Manyi, Tibet earthquake from linear elastic modeling of InSAR displacement. Geophys. J. Int. 169,988-1088. earthquakes along the Xidatan-Dongdatan Segment of the Kunlun Fault, Western China. Bull. Seismol. Soc. Am. 96 (1), 48-58, doi: 10.1785/0120040176. 
Guo, J., Lin, A., Sun, G., Zheng, J., 2007. Surface Ruptures Associated with the 1937 M 7.5 Tuosuo Lake and the 1963 M 7.0 Alake Lake Earthquakes and the Paleoseismicity along the Tuosuo Lake Segment of the Kunlun Fault, Northern Tibet. Bull. Seismol. Soc. Am., 97(2), 474-496, doi: 10.1785/0120050103.

Harris, R. A., Simpson, R. W., Reasenberg, P. A., 1995. Influence of static stress changes on earthquake locations in southern California. Nature 375, 221-224.

Heidbach, O and Ben-Avraham, A., 2007, Stress evolution and seismic hazard of the Dead Sea fault system. Earth Planet. Sci. Lett. 257, 299-312.

Hergert, T., and Heidbach O., 2006, New insights into the mechanism of postseismic stress relaxation exemplified by the 23 June $2001 \mathrm{Mw}=8.4$ earthquake in southern Peru. Geophys. Res. Lett., 33, L02307, doi:10.1029/ 2005GL024858.

Hodgkinson, K.M., Stein, R.S., Marshall, G., 1996. The 1954 Rainbow MountainFairview Peak-Dixie Valley earthquake sequences: a triggered normal faulting sequence. J. Geophys. Res., 101, 25 459-25 472.

Jaume, S. C., Sykes, L. R., 1996. Evolution of moderate seismicity in the San Francisco Bay region, 1850 to 1993 : seismicity changes related to the occurrence of large and great earthquakes. J. Geophys. Res. 101, 765-789.

Kidd, W. S. F., Molnar, P., 1988. Quaternary and active faulting observed on the 1985 Academia Sinica-Royal Society Geotraverse of Tibet. Phil. Trans. R. Soc. Lond. A. $327,337-63$.

King, G. C. P., Stein, R. S., Lin, J., 1994. Static stress changes and the triggering of earthquakes. Bull. Seismol. Soc. Am. 84, 935-953.

Lasserre, C., Peltzer, G., Crampe', F., Klinger, Y., Van der Woerd, J., Tapponnier, P., 2005. Coseismic deformation of the $2001 \mathrm{Mw}=7.8$ Kokoxili earthquake in Tibet, 
measured by synthetic aperture radar interferometry. J. Geophys. Res., 110, B12408, doi:10.1029/ 2004JB003500.

Li, C., Dai, H., Chen, Y., Xu, X., Dai, W., 2006a. The discussion on some problems of the Ms7.5 Tuosuohu Lake earthquake in 1937. Seisomology and Geology. 28(1), 12-21. (in Chinese with English abstract).

Li, H., Van der Woerd, J., Tapponnier, P., Klinger, Y., Qi X., Yang, J., Zhu Y., 2005. Slip rate on the Kunlun fault at Hongshui Gou, and recurrence time of great events comparable to the 14/11/2001, Mw 7.9 Kokoxili earthquake. Earth Planet. Sci. Lett. $237285-299$.

Li, Q., Peng, S., Gao, R., Guan, Y., Fan, J., 2004. Deep structure background of great earthquake in eastern Kunlun. Acta Geoscientica Sinica, 25(1), 11-16. (in Chinese with English abstract).

Li, Y., Wu, Q., An, Z., Tian, X., Zeng, R., Zhang, R., Li, H., 2006. The S-wave velocity structure and Poisson ratio of the northeastern margin of the Tibetan Plateau and its tectonic significance. Chinese Journal of Geophysics. 49(5), 1359-1368.

Lin, A., Guo, J., Kano, K., Awata, Y., 2006. Average Slip Rate and Recurrence Interval of Large-Magnitude Earthquakes on the Western Segment of the Strike-Slip Kunlun Fault, Northern Tibet. Bull. Seismol. Soc. Am. 96(5), 1597-1611, doi:

Lin, A., Fu, B., Guo, J., Zeng, Q., Dang, G., He, W., Zhao, Y., 2002. Coseismic strike-slip and rupture length produced by the Ms 8.1 Central Kunlun earthquake, Science 296, 2015-2017. Central Kunlun earthquake, China. Bull. Seism. Soc. Am. 93, 2477-2492. 
Liu, G. 1999. The surface rupture zone by 1937 Huashixia earthquake, in Eastern Kunlun Active Fault Zone, Seismological Bureau of Qinghai Province and Institute of Crustal Dynamics. China Seismological Bureau (Editors), Seismological Press, Beijing, 127156 (in Chinese).

Liu, R., Chen, Y., Krueger, F., Cheng, J., 2000. Higher degree moment tensor inversion of Mani earthquake using far-field broad-band recording. Acta Seismologica Sinica, 22(3), 226-232. (in Chinese with English abstract).

Lorenzo-Martín, F., Roth, F., Wang, R. J., 2006. Elastic and inelastic triggering of earthquakes in the North Anatolian Fault zone. Tectonophysics 424, 271-289.

Ma, K.-F., Chan, C.-H., Stein, R. S., 2005. Response of seismicity to Coulomb stress triggers and shadows of the $1999 \mathrm{Mw}=7.6 \mathrm{Chi}-\mathrm{Chi}$, Taiwan, earthquake. J. Geophys. Res. 110, B05S19, doi:10.1029/2004JB003389.

Martínez-Díaz, J.J., Capote, R., Tsige, M., Villamor, P., Martín-González, F., InsuaArévalo, J.M., 2006. Seismic triggering in a stable continental area: The Lugo 19951997 seismic sequences (NW Spain). J. Geodyn. 41, 440-449.

McCloskey, J., Nalbant, S.S., Steacy, S., 2005. Earthquake risk from co-seismic stress. Nature, 434 (7031), 291.

Molnar, P., Chen, W.P., 1983. Focal depths and fault plane solutions of earthquakes under the Tibetan plateau. J. Geophys. Res. 88, 1180-1196.

Molnar, P., Deng, Q., 1984, Faulting associated with large earthquakes and the average rate of deformation in central and eastern Asia. J . Geophys. Res., 89(B7), 6203-6227.

Molnar, P., Lyon-Caen, H., 1989. Fault plane solutions of earthquakes and active tectonics of the Tibeteau and its margins. Geophys. J . Int ., 99, 123-153. 
593 Nalbant, S.S., Hubert, A., King, G.C.P., 1998. Stress coupling between earthquakes in 594 northwest Turkey and the north Aegean Sea, J. Geophys. Res., 103, 24 469-24 486.

595 Nalbant, S.S., Steacy, S., McCloskey, J., Sieh, K., Natawidjaja, D., 2005. Earthquake risk 596 on the Sunda trench. Nature 435 (7043), 756-757.

597 Okada, Y., 1992. Internal deformation due to shear and tensile faults in a half-space, Bull. $598 \quad$ Seismol. Soc. Am., 82, 1018-1040.

599 Parsons, T., Stein, R.S., Simpson, R.W., Reasenberg, P.A., 1999. Stress sensitivity of fault 600 seismicity: a comparison between limited-offset oblique and major strike-slip faults, J. $601 \quad$ Geophys. Res., 104, 20 183-20 202.

602 Peltzer, G., Crampé, F., King, G., 1999. Evidence of nonlinear elasticity of the crust from 603 the Mw 7.6 Manyi (Tibet) earthquake. Science 286, 272-276.

604 Pollitz, F. F., 1997. Gravitational-viscoelestic postseismic relaxation on a layered spherical 605 Earth. J. Geophys. Res., 102, 17921-17941.

606 Pollitz, F.F., Bürgmann, R., Segall, P., 1998. Joint estimation of afterslip rate and 607 postseismic relaxation following the 1989 Loma Prieta earthquake. J. Geophys. Res., $608 \quad$ 103(B11), 26975-26992.

609 Pollitz, F.F., Sacks, I.S., 2002. Stress triggering of the 1999 Hector Mine earthquake by 610 transient deformation following the 1992 Landers Earthquake. Bull. Seism. Soc. Am., 611 92(4), 1487-1496; DOI: 10.1785/0120000918.

612 Pollitz, F., Vergnolle, M., Calais, E., 2003. Fault interaction and stress triggering of 613 twentieth century earthquakes in Mongolia. J. Geophys. Res., 108(B10), 2503, 614 doi:10.1029/ 002JB002375. 
615 Pollitz, F.F., Wicks, C., Thatcher, W., 2001. Mantle flow beneath a continental strike - slip 616 fault: postseismic deformation after the 1999 Hector Mine earthquake. Science 293 $617 \quad$ (5536), 1814-1818.

618 Reasenberg, P. A., Simpson, R. W., 1992. Response of regional seismicity to the static 619 stress change produced by the Loma Prieta earthquake. Science 255, 1687-1690.

620 Ryder, I., Parsons, B., Wright, T. J., Funning, G. J., 2007, Post-seismic motion following 621

Savage, J.C., 1983. A dislocation model of strain accumulation and release at a subduction zone. J. Geophys. Res. 88, 4984-4996.

Scholz, C.H., 1990. The Mechanics of Earthquakes and Faulting. New York: Cambridge Univ. Press. pp 439.

Seismological Bureau of Qinghai Province (SBQP), Institute of Crustal Deformation, and

Shan, X., Ma, J., Wang, C., Liu, J., 2002. Extracting coseismic deformation of the 1997 Mani earthquake with differential interferometric SAR. Acta Seismologica Sinica,

Shao, Z.G., Fu, R.S., Xue, T.X., et al., 2008. The numerical simulation and discussion on mechanism of postseismic deformation after Kunlun Ms 8.1 earthquake. Chinese J.

Shen, Z., Wan, Y., Gan, W., Zeng, Y., Ren, Q., 2003. Viscoelastic triggering among large Geophys., 51(3), 805-816.

638 earthquakes along the eastern Kunlun fault system. Chinese Journal of Geophysics. 46(6), 786-795. 
639 Steacy, S.J., McCloskey, J., 1998. What controls an earthquake's size? Results from a 640 heterogeneous cellular automaton. Geophys. J. Int. 133 (1), F11-F14.

641 Stein, R. S., 1999. The role of stress transfer in earthquake occurrence. Nature 402, 605642609.

643 Stein, R.S., 2003. Earthquake Conversations. Scient. Am., 288, 72-79.

644 Stein, R. S., King, G. C. P., Lin, J., 1994. Stress triggering of the 1994 M=6.7 Northridge, 645 California, earthquake by its predecessors. Science 265 (5177), 1432-1435 .

646 Tapponnier, P., Molnar, P., 1997. Active faulting and tectonics in China. J. Geophys. Res. 647 82, 2905-2930.

Toda, S., Stein, R. S., Reasonberg, P. A., Dieterich, J. H., 1998. Stress transferred by the 649 $\mathrm{Mw}=6.5$ Kobe, Japan, shock: Effect on aftershocks and future earthquake 650 probabilities. J. Geophys. Res. 103, 24543-24565.

Van der Woerd, J., Ryerson, F.J., Tapponnier, P., Meriaux, A.S., Gaudemer, Y., Meyer, B., 652 Finkel, R.C., Caffee, M.W., Zhao, G., Xu, Z., 2000. Uniform slip-rate along the Kunlun Fault: implications for seismic behavior and large-scale tectonics. Geophys. Res. Lett. 27, 2353-2356.

Van der Woerd, J., Meiaux, A.S., Klinger, Y., Ryerson, F.J., Gaudemer, Y., Tapponnier, 656 P., 2002a. The November 14th, 2001, Mw=7.8 Kokoxili Earthquake in Northern Tibet (Qinghai Province, China). Seismological Research Letters 73, 144-154.

Van der Woerd, J., Tapponnier, P., Ryerson, F.J., Meriaux, A.S., Meyer, B., Gaudemer, Y., 659 Finkel, R.C., Caffee, M.W., Zhao, G., Xu, Z., 2002b. Uniform postglacial slip-rate along the central $600 \mathrm{~km}$ of the Kunlun fault (Tibet), from ${ }^{26} \mathrm{Al},{ }^{10} \mathrm{Be}$, and ${ }^{14} \mathrm{C}$ dating of riser offsets, and climatic origin of the regional morphology. Geophys. J. Int. 148, 356-388. 
663 Velasco, A.A., Ammon, C.J., Beck, S.L., 2000. Broadband source modeling of the 664 November 8, 1997, Tibet $(\mathrm{Mw}=7.5)$ earthquake and its tectonic implications. J. $665 \quad$ Geophys. Res. 105, 28065-28808.

666 Wang, H., Xu, C. J., Ge, L. L., 2007, Coseismic deformation and slip distribution of the 6671997 Mw7.5 Manyi, Tibet, earthquake from InSAR measurements. Journal of $668 \quad$ Geodynamics, 44, 200-212.

669 Wang, Q., Zhang, P., Freymueller, J. F., Bilham, R., Larson, K. M., Lai, X., You, X., Nie, 670 Z., Wu, J., Li, Y., Liu, J., Yang, Z., Chen, Q., 2001. Present-day crustal deformation

Wang, R., Lorenzo Martín, F., Roth, F., 2003. Computation of deformation induced by earthquakes in a multi-layered elastic crust - FORTRAN programs EDGRN/EDCMP.

Wang, R., Lorenzo-Martín, F., Roth, F., 2006. PSGRN/PSCMP-a new code for calculating 677 co- and post-seismic deformation, geoid and gravity changes based on the viscoelastic- gravitational dislocation theory. Comput. Geosci. 32, 527-541.

Wang, Y., Qian, H., 2000, Study of crustal velocity structure in the eastern Qinghai 680 Province. Earth Science Frontiers. 7(4), 568-579.

Wells, D.L., Coppersmith, K.J., 1994. New empirical relationships among magnitude, 682 rupture length, rupture width, rupture area, and surface displacement. Bull. Seism. 
687 Wessel, P., Smith, W.H.F., 1998, New, improved version of generic mapping tools 688 released. EOS Trans. 79(47), 579.

Wyss, M., Wiemer, S., 2000. Change in the probability for earthquakes in southern California due to the Landers magnitude 7.3 earthquake. Science, 290, 1334-1338.

Xu, L., Chen, Y., 1999. Spatial-temporal rupture process of Ms7.9 earthquake in Mani 692 China, 1997. Acta Seismologica Sinica, 21(5), 449-459.

$\mathrm{Xu}, \mathrm{X}$., 2000. Scientific survey for the Manyi earthquake. in: Y.C. Liu (Ed.), China Earthquake Yearbook, Seismological Press, Beijing, 2000, pp. 327- 329.

Xu, X., Chen, W., Ma, W., Yu, G., Chen, G., 2002. Surface ruptures of the Kunlunshan 696 earthquake (Ms 8.1), northern Tibetan Plateau, China. Seism. Res. Lett. 73, 884-892.

Xu, X., Yu, G., Klinger, Y., Tapponnier, P., Van der Woerd, J., 2006. Reevaluation of 698 surface rupture parameters and faulting segmentation of the 2001 Kunlunshan earthquake (Mw 7.8), northern Tibet Plateau, China, J. Geophys. Res. 111, B05316,

Yin, A., Harrison, T. M., 2000. Geologic evolution of the Himalayan Tibetan orogen. Annu. Rev. Earth Planet. Sci. 28:211-80.

Zhao, G., 1996. Quaternary faulting in North Qinghai-Tibet Plateau. Earthquake Res. China 12, 107-119 (in Chinese with English abstract).

Zhou, M., Zhang, Y., Shi, Y., Zhang, S., Fan, B., 2006. Three-dimensional crustal velocity structure in the northeastern margin of the Tibetan Plateau. Progress in Geophysics. 21(1), 127-134. 
709 Figure 1. Location map of the Kunlun fault region and spatial-temporal migration of five

$710 \mathrm{M} \geq 7.0$ earthquakes along the fault during the period 1937 to 2001 . Epicenter locations

711 (grey stars), event date and focal mechanisms are summarized in Table 1. Solid lines are

712 faults and thick solid lines are ruptured segments. Numbers inside open rectangles indicate

713 fault slip rates. Labels inside open rectangles are names of cities and towns. Locations of

714 cities and towns are indicated by symbols (solid dot: population 10-50 thousand; up solid

715 triangle: 50-100 thousand; down solid triangle: 100-200 thousand; solid square: $>200$

716 thousand). Inset shows the overview of the study reagion and indicates with a black star the

717 epicenter location of Mw7.9 Wenchuan earthquake.

719 Figure 2. Horizontally stratified model comprised of elastic upper crust, viscoelastic lower crust and viscoelastic mantle. $V_{P}$ is the velocity of $\mathrm{P}$ wave. $\mu$ is the shear modulus. $\rho$ is the rock density, and $\eta$ is viscosity ( $\eta_{c}$, crustal viscosity; $\eta_{m}$, mantle viscosity). $\eta_{c}$ and $\eta_{m}$ are set to be $1 \times 10^{18}$ and $\times 10^{20} \mathrm{~Pa} \cdot \mathrm{s}$, respectively. and other values of viscosities are used for comparison and stability tests.

Figure 3. Evolution of the Coulomb Failure Stress changes at the depth of $10 \mathrm{~km}$ since 1937. Thick lines are faults. Thick green, red and white lines represent the segment of the next earthquake rupture, the current earthquake rupture and the previous ruptured segments, respectively. Figures labelled from a to $\mathrm{f}$ are snapshots at different time: (a) immediately after the 1937 event; (b) immediately before the 1963 event; (c) immediately before the 1973 event; (d) immediately before the 1997 event; (e) immediately before the

7312001 event; (f) current state of the change in Coulomb Failure Stress in year 2008. 
733 Figure 4. Co- and combined (co- and post-seismic) change of Coulomb Failure Stress

734 from just before 1963 Alake Lake earthquake to just before 2001 Kokoxili earthquake as a 735 function of time for each hypocenter listed in Table 1.

738 Figure 5. Coulomb Failure Stress state of the KF in year 2040. Displayed are the 739 cumulative $\triangle$ CFS calculated for the varying orientation of each fault in 1-km steps. The $740 \triangle \mathrm{CFS}$ values (a) include co- and post-seismic stress changes; and (b) combined stress 741 change (co-, post-seismic stress change and tectonic loading). Units A-E are the five 742 segments on which $\triangle \mathrm{CFS}$ is positive. Meanings of symbols and labels refer to Fig. 1. From 743 west to east, the stress loaded units are labeled A) Western Manyi; B) Manyi-Kunlun 744 Transition Zone; C) Xidatan-Dongdatan Segment (XDS); D) Alake Lake-Tuosuo Lake 745 Segment (ATS) and E) Maqin-Maqu Segment (MMS).)

747 Figure 6. Evolution of the cumulative $\triangle \mathrm{CFS}$ (co- and post-seismic) on the segments of XDS (a) and MMS (b). Line 1937 indicates the $\triangle$ CFS just after 1937 Tuosuo Lake earthquake. Lines with number of year attached by "a" represent the $\triangle \mathrm{CFS}$ immediately before the earthquake, and those attached by "b" immediately after the earthquake. Line 2040 represents the $\triangle$ CFS state of the year of 2040 . 
Table 1 Source parameters of the sequence of earthquakes used in this study

\begin{tabular}{|c|c|c|c|c|c|c|c|c|c|}
\hline $\mathrm{Y} / \mathrm{M} / \mathrm{D}$ & $\begin{array}{l}\text { Latitude } \\
\qquad\left({ }^{\circ} \mathrm{N}\right)\end{array}$ & $\begin{array}{l}\text { Longitude } \\
\qquad\left({ }^{\circ} \mathrm{E}\right)\end{array}$ & $\begin{array}{c}\text { Strike/Dip/Rake } \\
\left({ }^{\circ}\right)\end{array}$ & $\begin{array}{l}\text { Length } \\
(\mathrm{km})\end{array}$ & Magnitude & $\begin{array}{c}\mathrm{M}_{0} \\
\left(10^{18} \mathrm{Nm}\right)\end{array}$ & $\begin{array}{l}\text { Slip }^{\#} \\
\text { (m) }\end{array}$ & Ref. & Location \\
\hline $1937 / 01 / 07$ & 35.40 & 97.69 & $110 / 70 / 15$ & 150 & M7.5 & 500 & 4.1 & $\begin{array}{c}1,2, \\
3\end{array}$ & $\begin{array}{c}\text { Tuosuo } \\
\text { L. }\end{array}$ \\
\hline $1963 / 04 / 19$ & 35.53 & 96.44 & $277 / 80 /-10$ & 40 & M7.0 & 32 & 1 & 1,4 & Alake L. \\
\hline $1973 / 07 / 14$ & 35.18 & 86.48 & $81 / 60 /-35$ & $66^{*}$ & M7.3 & 79.2 & $1.5^{*}$ & $\begin{array}{c}2,4, \\
5\end{array}$ & Manyi \\
\hline $1997 / 11 / 08$ & 35.25 & 87.25 & $76 / 90 /-5$ & 170 & Mw7.6 & $252 \sim 284$ & - & 6,7 & Manyi \\
\hline $2001 / 11 / 14^{\mathrm{a}}$ & 35.82 & 92.85 & & & & & & & \\
\hline $2001 / 11 / 14^{b}$ & 35.95 & 90.54 & $99 / 90 / 5$ & 400 & Mw7.8 & 592 & - & 8 & Kokoxili \\
\hline
\end{tabular}

760 The references used are: 1 Guo et al., 2007; 2 Molnar and Deng, 1984; 3 J. Van der Woerd, et al., $2002 ; 4$

761 Molnar and Lyon-Caen, 1989; 5 Molnar and Chen, 1983; 6 Funning et al., 2007; 7 Xu, 2000; 8 Lasserre et

762 al., 2005.

763 \#: Slip amplitudes of 1937, 1963 and 1973 earthquakes were estimated by assuming a locking depth $w$ of 20

$764 \mathrm{~km}$ using the empirical relations of Wells and Coppersmith (1994)

$765 *$ : The Length of the rupture and the slip amplitude were estimated by using empirical scaling laws by Wells

766 and Coppersmith (1994).

767 a and b: Locations of hypocenter were given by Harvard CMT (a) and USGS (b).

768 - Slip distributions were given by cited references. 
772 Table 2 Accumulated $\triangle \mathrm{CFS}$ at hypocenters and along rupture of earthquakes on KF

\begin{tabular}{|c|c|c|c|c|c|c|c|c|c|c|}
\hline \multirow[b]{2}{*}{ No. } & \multirow[b]{2}{*}{ Date } & \multirow{2}{*}{$\begin{array}{l}\text { Lat. } \\
\left({ }^{\circ} \mathrm{N}\right)\end{array}$} & \multirow{2}{*}{$\begin{array}{l}\text { Long. } \\
\left({ }^{\circ} \mathrm{E}\right)\end{array}$} & \multicolumn{3}{|c|}{ At hypocenter } & \multicolumn{3}{|c|}{ Along rupture plane } & \multirow[b]{2}{*}{ Location } \\
\hline & & & & $\begin{array}{c}\Delta \sigma_{\mathrm{c}} \\
(\mathrm{MPa})\end{array}$ & $\begin{array}{l}\Delta \sigma_{\mathrm{c}+\mathrm{p}} \\
(\mathrm{MPa})\end{array}$ & $\begin{array}{c}\Delta \sigma_{\mathrm{t}} \\
(\mathrm{MPa})\end{array}$ & $\begin{array}{l}\Delta \sigma_{\max } \\
(\mathrm{MPa})\end{array}$ & $\begin{array}{l}\Delta \sigma_{\text {ave }} \\
(\mathrm{MPa})\end{array}$ & $\begin{array}{c}\mathrm{P} \\
(\%)\end{array}$ & \\
\hline 1 & $1937-01-07$ & 35.40 & 97.69 & - & - & - & - & - & - & Alake L. \\
\hline 2 & 1963-04-19 & 35.53 & 96.44 & 0.014 & 0.086 & 0.036 & 0.11 & 0.06 & 100 & Tuosuo L. \\
\hline 3 & $1973-07-14$ & 35.18 & 86.48 & $4.9 \times 10^{-5}$ & $4.5 \times 10^{-4}$ & 0.051 & $4.52 \times 10^{-4}$ & $3.14 \times 10^{-4}$ & 0 & Manyi \\
\hline 4 & 1997-11-08 & 35.25 & 87.25 & 0.013 & 0.038 & 0.083 & 0.25 & 0.063 & 98 & Manyi \\
\hline \multirow[t]{2}{*}{5} & $2001-11-14^{\mathrm{a}}$ & 35.82 & 92.85 & 0.001 & 0.01 & 0.21 & \multirow[t]{2}{*}{0.04} & \multirow[t]{2}{*}{0.014} & \multirow[t]{2}{*}{42.7} & \multirow[t]{2}{*}{ Kokoxili } \\
\hline & $2001-11-14^{\mathrm{b}}$ & 35.95 & 90.54 & 0.001 & 0.0046 & 0.069 & & & & \\
\hline
\end{tabular}

773 (a: Epicenter of the Mw7.8 Kokoxili earthquake given by the Harvard CMT; b: Epicenter

774 given by USGS.)

775 P: Percentage of rupture length with $\Delta \sigma \geq 0.01 \mathrm{MPa}$;

$776 \Delta \sigma_{\mathrm{c}}:$ coseismic CFS change; $\Delta \sigma_{\mathrm{c}+\mathrm{p}}:$ coseismic + postseismic CFS change;

$777 \Delta \sigma_{\mathrm{t}}:$ stress change due to tectonic loading; $\Delta \sigma_{\max }:$ Maximum of $\Delta \sigma \mathrm{c}+\mathrm{p}$;

$\Delta \sigma_{\text {ave }}:$ Averaged $\Delta \sigma c+p$ 
796 Table 3 Accumulated $\Delta$ CFS (co- and post-seismic) at hypocenters of earthquakes on KF

\begin{tabular}{|c|c|c|c|c|c|c|}
\hline \multirow{2}{*}{\multicolumn{2}{|c|}{ Viscosiy $\left(\times 10^{18} \mathrm{~Pa} \cdot \mathrm{s}\right)$}} & \multicolumn{5}{|c|}{$\Delta \sigma_{\mathrm{c}+\mathrm{p}}(\mathrm{MPa})$ on hypocenter } \\
\hline & & 1963 & 1973 & 1997 & $2001 \mathrm{a}$ & $2001 b$ \\
\hline \multirow{3}{*}{$\eta_{\mathrm{m}}=100$} & $\eta_{\mathrm{c}}=0.5$ & 0.095 & $11 \times 10^{-4}$ & 0.042 & 0.012 & 0.0055 \\
\hline & $\eta_{c}=1.0$ & 0.086 & $4.5 \times 10^{-4}$ & 0.038 & 0.010 & 0.0046 \\
\hline & $\eta_{c}=10$ & 0.047 & $0.85 \times 10^{-4}$ & 0.021 & 0.0037 & 0.001 \\
\hline \multirow{5}{*}{$\eta_{c}=1$} & $\eta_{\mathrm{m}}=0.5$ & 0.1046 & $2.55 \times 10^{-3}$ & 0.046 & 0.018 & 0.0096 \\
\hline & $\eta_{\mathrm{m}}=1.0$ & 0.1016 & $2.1 \times 10^{-3}$ & 0.045 & 0.016 & 0.0084 \\
\hline & $\eta_{\mathrm{m}}=5.0$ & 0.092 & $1.1 \times 10^{-3}$ & 0.041 & 0.012 & 0.0058 \\
\hline & $\eta_{\mathrm{m}}=10$ & 0.089 & $0.78 \times 10^{-3}$ & 0.04 & 0.011 & 0.0052 \\
\hline & $\eta_{\mathrm{m}}=100$ & 0.086 & $0.45 \times 10^{-3}$ & 0.038 & 0.01 & 0.0046 \\
\hline
\end{tabular}

797

798

799 